\title{
PENGARUH MARKETING MIX TERHADAP KEPUTUSAN PEMBELIAN BELANJA ONLINE DI APLIKASI SHOPEE PADA MAHASISWA PRODI MANAJEMEN UNIVERSITAS PGRI ADI BUANA SURABAYA
}

\author{
Afifatul Hamidah ${ }^{1}$, Martha Suhardiyah² \\ Universitas PGRI Adi Buana Surabaya1,2,3 \\ afifatulhamidah52@gmail.com
}

\begin{abstract}
ABSTRAK
Keputusan pembelian itu adalah pandangan ketika seseorang mengevaluasi bermacam pilihan serta membuat putusan terhadap product dari bebagai pilihan. Tujuan penelitian untuk memahami pengaruh marketing mixterhadap keputusan pembelian belanja online di aplikasi shopee pada mahasiswa prodi manajemen Universitas PGRI Adi Buana Surabaya. Pendekatan kuantitatif yang digunakan dalam penelitian, sampel dipakai sebanyak 90 responden dengan teknik pengambilan sampel yaitu simple randaom sampling. Penelitian dilakukan dengan penyebaran kuesioner dan dokumentasi. Teknik analisi yang diterapkan adalah Teknik analisis linier berganda. Hasil penelitian membuktikan jika marketing mix memiliki pengaruh signifikan dan positif terhadap keputusan pembelian.
\end{abstract}

Kata kunci: Marketing Mix, Keputusan Pembelian

\begin{abstract}
The purchasing decision is a challenge in which individuals make various choices and decide on the product of the many choices. The porpose this studi to consider efect marketing mix on online shopping purchase decisions in the shopee application of management students at PGRI Adi Buana University Surabaya. This studi uses quantitative, samples taken as many as 90 respondents with a sampling technique that is simple randaom sampling. The study conducted by distributing questionnaires and documentation. The analysis technique applied is multiple linear analysis techniqu. results the studi prove to the marketing mix have significant and positive efect on purchasing decision.
\end{abstract}

Keywords : Marketing Mix, Purchase Decision 


\section{PENDAHULUAN}

Perkembangan zaman yang diikuti dengan kemajuan teknologi saat ini menyebabkan setiap orang harus mampu bersaing untuk mengikuti kemajuan teknologi. Kemajuan teknologi menyebabkan perubahan pada beberapa aspek kehidupan. Salah satunya adalah perubahan dalam hal berbelanja. Terjadinya kemajuan teknologi membuat munculnya aplikasi belanja online (Peneliti, 2019).

Dengan adanya kemudahan yang ditawarkan oleh aplikasi belanja online, maka

Di Indonesia, aplikasi belanja online sudah digunakan masyarakat, salah satunya aplikasi belanja online SHOPPE. SHOPEE sebagai situs penjualan online atau e-commerce paling terviral dipakai masyarakat Indonesia. penelitian online yang dibuat Snapcart dari 6.000 responden periode Januari 2018 ditemukan hal menarik hingga 37\% dari pengakuan responden pengguna SHOPEE. hingga SHOPEE ada di urutan nomor satu yang paling banyak digunakan di belanja online.

Di dalam penjualan pada aplikasi SHOPEE terdapat marketing mix yang dapat menarik keputusan pembeli. Menurut Kotler dan Amstrong (2012:75) "Marketing mix is the set of tactical marketing tools that the firm blends to produce the response it wants in the target market". Bauran pemasaran diartikan sebagai alat pemasaran yang dipakai perusahaan secara terus menerus dalam mencapai tujuan perusahaanya dipasar yang dituju. Di Indonesia SHOPEE sudah di unduh 80 juta unduhan dan 2,2 juta penjual.

Pada bauran pemasaran (marketing mix) ada beberapa 7 unsur. Unsur pertama ialah Product (produk), produk adalah suatu yang dipasarkan dipasaran. Unsur yang kedua ialah Price (harga) dipergunakan untuk diberi nilai financial oleh produk atau jasa.

Selanjutnya unsur ketiga ialah Promotion (promosi) yaitu menawarkan suatu produk atau jasa yang dijual, baik melalui media social maupun media online. Untuk unsure yang keempat ialah Place (tempat) dimana usaha dijalankan untuk menjual produk maupun jasa,. Selain unsur tersebut, ada unsur kelima ialah Partisipant (orang) yang masuk dan turut dalam memasarkan produk. Unsur selanjutnya ialah Proces (proses), bagaimana pelayanan penjual hingga barang yang dibeli sampai kepada konsumen.Unsur yang ketujuh ialah Physical Evidence (tampilan fisik), yaitu fasilitas yang digunakan untuk melayani konsumen.

Bauran pemasaran bertujuan buat mengetahui informasi tentang produk dan jasa oleh target konsumen dan untuk penjualan lebih menguntungkan. Dengan adanya informasi yang diterima konsumen diharapkan konsumen mengerti dan berminat dengan produk atau jasa yang ditawarkan. Bauran pemasaran bermanfaat untuk meningkatkan penjualan melalui pemasaran yang dilakukan penjual barang atau jasa. Pemasaran terus dilakukan selama produksi barang yang akan dijual masih berjalan.

Aplikasi SHOPEE merupakan aplikasi belanja online yang mudah digunakan kapanpun dan dimanapun, maka dari itu mahasiswa yang sibuk dengan kegiatan kampus apabila ingin berbelanja kebutuhan sehari-hari namun tidak punya waktu luang, dapat berbelanja melalui SHOPEE tanpa menyita waktu banyak namun barang yang diinginkan bisa didapatkan. 
Dari uraian diatas yang menjadi alasan peneliti akan melakukan penelitian degan judul "Pengaruh Marketing Mix Terhadap Keputusan Pembelian Belanja Online Di Aplikasi SHOPEE Pada Mahasiswa Prodi Manajemen Universitas PGRI Adi Buana Surabaya".

\section{RUMUSAN MASALAH}

Berdasarkan uraian tersebut, maka penulis mengindentifikasi beberapa masalah berikut:

1. Apakah Product berpengaruh secara parsial terhadap Keputusan Pembelian belanja online di SHOPEE pada Mahasiswa Prodi Manajemen Universitas PGRI Adi Buana Surabaya?

2. Apakah Price berpengaruh secara parsial terhadap Keputusan Pembelian belanja online di SHOPEE pada Mahasiswa Prodi Manajemen Universitas PGRI Adi Buana Surabaya?

3. Apakah Promotion berpengaruh secara parsial terhadap Keputusan Pembelian belanja online di SHOPEE pada Mahasiswa Prodi Manajemen Universitas PGRI Adi Buana Surabaya?

4. Apakah Place berpengaruh secara parsial terhadap Keputusan Pembelian belanja online di SHOPEE pada Mahasiswa Prodi Manajemen Universitas PGRI Adi Buana Surabaya?

5. Apakah Partisipant berpengaruh secara parsial terhadap Keputusan Pembelian belanja online di SHOPEE pada Mahasiswa Prodi Manajemen Universitas PGRI Adi Buana Surabaya?

6. Apakah Proces berpengaruh secara parsial terhadap Keputusan Pembelian belanja online di SHOPEE pada Mahasiswa Prodi Manajemen Universitas PGRI Adi Buana Surabaya?

7. Apakah Physical Evidence berpengaruh secara parsial terhadap Keputusan Pembelian belanja online di SHOPEE pada Mahasiswa Prodi Manajemen Universitas PGRI Adi Buana Surabaya?

8. Apakah Product, Price, Promotion, Place, Partisipant, Proces, dan Physical Evidence berpengaruh secara simultan terhadap Keputusan Pembelian belanja online di SHOPEE pada Mahasiswa Prodi Manajemen Universitas PGRI Adi Buana Surabaya?

\section{METODE}

Penelitianini menggunakan pendekatan kuantitatif. penelitian diadakan dikampus Universitas PGRI Adi Buana di gedung fakulitas ekonomi yang berlokasi di Jl. Dukuh Menanggal XII No. 17 Surabaya. Populasinya merupakan mahasiswa prodi manajemen angkatan 2016-2019 sejumlah 914 mahasiswa. Sampel sejumlah 90 responden sedangkan teknik pengambilan sampel yaitu simple random sampling. Data primer dipergunakan oleh penulis. Dimana subjeknya adalah responden berupa manusia yaitu mahasiswa prodi manajemen angkatan 2016-2019. Sumber data yang diperlukan Oleh penulis adalah data primer dan data skunder. Bahwa data primer didapat oleh penulis dengan cara menyebar questioner. Data skunder dalam penelitian ini dikumpulkan dari kampus, serta sumber lain yang mendukung penelitian. Pengumpulan data dilaksanakan dengan penyebaran kuesioner dengan penggunaan skala likert. Teknik analisis memprgunakan analisis linier beganda.

\section{HASIL}


Berikut adalah hasil penelitian yang telah dilakukan oleh 90 responden dengan melalui questioner.

1. Berdasarkan hasil perhitungan Menunjukkan analisis data dari variabel product(X1) dengan sampel 90 responden, tanggapan responden dari indicator variabel product(X1)mempunyai nilai rata-rata sebesar 4,21 dengan kategori Tinggi. Yang artinya product yang dijual melalui aplikasi shoopee menurut responden mempunyai kualitas yang sangat baik.

2. Berdasarkan hasil perhitungan Menunjukkan analisis data dari variabel price (X2)dengan sampel 90 responden, tanggapan responden dari indicator variabel price (X2) bernilai rata-rata sebesar 3,76 dengan kategori lumayan Tinggi. Yang artinya harga product yang dijual melalui aplikasi shoopee menurut responden cukup terjangkau dan kompetitif.

3. Berdasarkan hasil Menunjukkan analisis data dari variabel promotion(X3) dengan sampel 90 responden, tanggapan responden dari indicator variabel promotion(X3) bernilai rata-rata sebesar 3,90 dengan kategori lumayan Tinggi. Yang artinya promosi product yang dilakukan shoopee menurut responden cukup baik dan dapat mempengaruhi konsumen untuk membeli.

4. Berdasarkan hasil perhitungan Menunjukkan analisis data dari variabel place (X4) dengan sampel 90 responden, tanggapan responden dari indicator variabel place (X4) bernilai rata-rata sebesar 3,97 dengan kategori lumayan Tinggi. Yang artinya mitra penjualyang menjual produk melalui aplikasi shoopee menurut responden dapat dipercaya dan mengirim barang sesuai dengan barang yang dibeli konsumen.

5. Berdasarkan hasil perhitungan Menunjukkan analisis data dari variabel partisipant(X5) dengan sampel 90 responden, tanggapan responden dari indicator variabel partisipant $(X 5)$ bernilai rata-rata sebesar 3,91 dengan kategori lumayan Tinggi. Yang artinya orang yang menjual produk melalui aplikasi shoopee menurut responden memberikan pelayanan yang sangat baik.

6. Berdasarkan hasil perhitungan Menunjukkan analisis data dari variabel proces(X3) dengan sampel 90 responden, tanggapan responden dari indicator variabel proces(X3) bernilai rata-rata sebesar 3,97 dengan kategori lumayan Tinggi. Yang artinya proses pembelian melalui aplikasi shoopee menurut responden mudah dan barang terkirim dengan cepat.

7. Berdasarkan hasil perhitungan Menunjukkan analisis data dari variabel Physical evidence (X7) dengan sampel 90 responden, tanggapan responden dari indicator variabel Physical evidence (X7) bernilai rata-rata sebesar 4,09 dengan kategori lumayan Tinggi.Yang artinya custumer percaya dan tidak takut dalam berbelanja melalui aplikasi shoopee karena shoope mempunyai kantor dan gudang sehingga custumer yakin tidak akan tertipu.

8. Berdasarkan hasil perhitungan Melihatkan analisis data dari variabel keputusan pembllian $(Y)$ dengan sampel 90 responden, tanggapan responden dari indicator variabel keputusan pembelian ( $Y$ ) bernilai mean 4,05 dengan kategori lumayan Tinggi. Yang artinya keputusan pembelian cutumer melalui aplikasi shoopee menurut responden cukup tinggi. Karena shoope sangat terkenal dan product yang dijual bagus dan harganya relative terjangkau. 


\section{UJI VALIDITAS}

Berdasarkan hasil pengujian tersebut menunjukkan jika seluruh item pada pernyataan diatas memiliki nilai sig $<0,05$. Maka semua pernyataan pada kuisioner diatas dapat dinyatakan valid. Sehingga peneliti dapat melanjutkan pengujian ke tahap berikutnya.

\section{UJI REALIBILITAS}

Dari hasil pengujian yang sudah dilakukan, oleh karena itu hasil pengujian uji reliabilitas didapat nilai koefisien reliabitas alpha Cronbach pada variabel product (X1) sebesar 0,954, variabel price $(X 2)$ sejumlah 0,897 , variabelpromotion $(X 3)$ sejumlah 0,881 , variabel place $(X 4)$ sejumlah0,726, variabel participant (X5) sejumlah 0,951, variabel process (X6) sejumlah 0,898, variabel physical evidence sejumlah 0,789 dan variabel keputusan pembelian (Y) sejumlh 0,945. keseluruhan variabel memperlihatkan nilai koefisien reliabitas Cronbach alpha lebih dari 0,60. Maka masalah ini dinyatakan jika seluruh variabel reliabel, sehingga kuesioner yang dibuat sebagai bahan acuan untuk penelitian dapat diterima responden dengan baik dan layak untuk dilanjutkan sebagai instrument penelitian.

\section{ANALISIS REGRESI LINIAR BERGANDA}

Setelah peneliti melakukan uji asumsi klasik, maka selanjutnya peneliti akan menganalisis data memakai multiple linerar regression. Analisis regresi berganda guna menentukan pengaruh dan arah hubungan variabel terikat dengan variabel bebas.

\section{PEMBAHASAN}

\section{Product $\left(\mathrm{X}_{1}\right)$ berpengaruh terhadap Variabel Keputusan Pembelian $(\mathrm{Y})$.}

Hasil dari pengujian hipotesis 1 menggunakan Uji-t. diperoleh nilai sig< 0,05. Rartinya jika sudah dinyatakan Hipotesis diterima. Dimaksudkan Product secara parsial berpengaruh positif dan signifikan terhadap Keputusan Pembelian belanja online di SHOPEE pada Mahasiswa Prodi Manajemen Universitas PGRI Adi Buana Surabaya. Hasil penelitian yang dilakunan oleh Nur Munifah (2014). dari perhitungan memakai SPSS diartikan bahwa inovasi produk secara signifikan berpengaruh secara positif terhadap keputusan pembelian dengan ( $p$ value $)=0,000<\alpha(0,05)$.

\section{Price $\left(\mathrm{X}_{2}\right)$ berpengaruh terhadap Variabel Keputusan Pembelian ( $\mathrm{Y}$ ).}

Hasilpengujian hipotesis 2 menggunakan Uji-t. diperoleh nilai sig sebesar $<0,05$. dimaksudkan jika dapat dinyatakan Hipotesis diterima. Yang artinya Price secara parsial mempengaruhi secara negatif dan signifkan terhadap Keputusan Pembelian belanja online di SHOPEE pada Mahasiswa Prodi Manajemen Universitas PGRI Adi Buana Surabaya. Penelitian ini sejalan dengan penelitian yang pernah dilakukan oleh Nur Munifah (2014). Berdasarkan hasil perhitungan dengan menggunakan SPSS diketahui bahwa harga secara signifkan berpengaruh secara positif terhadap keputusan pembelian dengan ( $p$ value) $=0,000<\alpha(0,05)$. 


\section{Promotion $\left(X_{3}\right)$ berpengaruh terhadap Variabel Keputusan Pembelian $(Y)$.}

hasil menunjukkan hipotesis 3 menggunakan Uji-t. diperoleh nilai sig< 0,05.hasil tersebut menandakan Hipotesis diterima. jika Promotion secara parsial mempengarui positif dan signifikan terhadap Keputusan Pembelian belanja online di SHOPEE pada Mahasiswa Prodi Manajemen Universitas PGRI Adi Buana Surabaya. Hasil penelitian sejalan dengan penelitian yang pernah dilakukan olehZamroni (2010). Hasil penelitian menunjukkan jika ada pengaruh variable promosi terhadap keputusan pembelian.

\section{4. $\quad$ Place $\left(\mathrm{X}_{4}\right)$ berpengaruh terhadap Variabel Keputusan Pembelian $(\mathrm{Y})$.}

hasil manunjukkan hipotesis 4 menggunakan Uji-t.Diperolehnilai sig< 0,05. disimpulkan bahwa Hipotesis diterima. Sehingga disebukan jika memilki pengaruh dan signifkan jikaPembelian belanja online di SHOPEE pada Mahasiswa Prodi Manajemen Universitas PGRI Adi Buana Surabaya. Hasil penelitian ini juga sejalan dengan penelitian yang pernah dilakukan oleh Januarista Poppy Mercelina Suratman (2018).Dimana hasil menyatakan bahwa Place $\left(X^{4}\right)$ mempengarui serta signifikan terhadap keputusan berkunjung.

\section{Partitipant $\left(\mathrm{X}_{5}\right)$ berpengaruh terhadap Variabel Keputusan Pembelian ( $\left.\mathrm{Y}\right)$.}

Hasilpengujian hipotesis 5 menggunakan Uji-t.diperoleh nilai sig< 0,05. Dapat diartikan jika Hipotesis diterima. Disebutkan Partisipant secara parsial berpengaruh positif dan signifkan terhadap Keputusan Pembelian belanja online pada SHOPEE pada Mahasiswa Prodi Manajemen Universitas PGRI Adi Buana Surabaya. Hasil penelitian ini juga sejalan dengan penelitian yang pernah dilakukan oleh Januarista Poppy Mercelina Suratman (2018). Dimana hasil menyatakan bahwa People (X5)berpengaruh signifikan terhadap keputusan berkunjung. hasilini menunjukkan jika sejalan dengan penelitian yang pernah dilakukan oleh Faisal Rakhman (2018). Dapat dinyatakan bahwa Terdapat pengaruh dan signifikan people terhadap keputusan mahasiswa memilih STIBANKS AI Ma'soem.

\section{Proces $\left(\mathrm{X}_{6}\right)$ berpengaruh terhadap Variabel Keputusan Pembelian $(\mathrm{Y})$.}

Hasil pengujian hipotesis 6 menggunakan Uji-t.diperolehnilai sig< 0,05.terlihat bahwa Hipotesis diterima. Yang artinya Proces secara parsial mempunyai pengaruhpositif dan signifikan terhadap Keputusan Pembelian belanja online di SHOPEE pada Mahasiswa Prodi Manajemen Universitas PGRI Adi Buana Surabaya. Hasil penelitian ini juga sejalan dengan penelitian yang pernah dilakukan oleh Faisal Rakhman (2018). Hasil penelitian menyatakan bahwa Terdapat pengaruh dan signifikan process terhadap keputusan mahasiswa memilih STIBANKS AI Ma'soem. 


\section{Physical evidence $\left(\mathrm{X}_{7}\right)$ berpengaruh terhadap Variabel Keputusan Pembelian $(\mathrm{Y})$.}

Hasil pengujian hipotesis 7 menggunakan Uji-t.diperolehnilai sig< 0,05. Dapat diartikan Hipotesis diterima. Yang artinya Physical evidence secara parsial berpengaruh positif dan signifikan terhadap Keputusan Pembelian belanja online di SHOPEE pada Mahasiswa Prodi Manajemen Universitas PGRI Adi Buana Surabaya.Pengaruh Physical evidence terhadap Keputusan Pembelianmempunyai nilai positif, yang artinya setiap peningkatan nilai Physical evidence, maka akan meningkatkan nilai Keputusan Pembelian. Hasil penelitian ini juga sejalan dengan penelitian yang pernah dilakukan oleh Faisal Rakhman (2018). Hasil menyebutkan jika Terdapat pengaruh dan signifikan Physical Evidence terhadap keputusan mahasiswa memilih STIBANKS AI Ma'soem.

\section{Product, Price, Promotion, place, participant, process dan physical evidencesecara simultan berpengaruh terhadap Variabel Keputusan Pembelian ( $Y$ ).}

Hasil pengujian hipotesis 8 menggunakan Uji-F. diperoleh nilai sigsebesar< 0,05.Dari hasil tersebut maka dapat dinyatakan Hipotesis diterima. Yang artinya Product, Price, Promotion, Place, Partisipant, Proces, dan Physical Evidencesecara simultan berpengaruh berpengaruh positif dan signifikan terhadap Keputusan Pembelian belanja online di SHOPEE pada Mahasiswa Prodi Manajemen Universitas PGRI Adi Buana Surabaya. Pengaruh Product, Price, Promotion, Place, Partisipant, Proces, dan Physical Evidencesecara simultan terhadap keputusan pembelian mendapatkan hasil positif, yang artinya setiap peningkatan nilai Product, Price, Promotion, Place, Partisipant, Proces, dan Physical Evidencesecara simultan, maka akan meningkatkan nilai keputusan pembelian.

\section{SIMPULAN}

Hasil penelitian dilaksanakan oleh peneliti dari hasil pengujian hipotesis dan pembahasan pada bab sebelumnya, maka simpulan untuk penelitian ini adalah :

1. Berdasarkan hasil perhitungan Menunjukkan analisis data dari variabel product( $X 1)$ dengan sampel 90 responden, tanggapan responden dari indicator variabel product(X1)mempunyai nilai rata-rata sebesar 4,21 dengan kategori Tinggi. Yang artinya product yang dijual melalui aplikasi shoopee menurut responden mempunyai kualitas yang sangat baik.

2. Berdasarkan hasil perhitungan Menunjukkan analisis data dari variabel price (X2)dengan sampel 90 responden, tanggapan responden dari indicator variabel price (X2) bernilai rata-rata sebesar 3,76 dengan kategori lumayan Tinggi. Yang artinya harga product yang dijual melalui aplikasi shoopee menurut responden cukup terjangkau dan kompetitif.

3. Berdasarkan hasil Menunjukkan analisis data dari variabel promotion $(\mathrm{X} 3)$ dengan sampel 90 responden, tanggapan responden dari indicator variabel promotion(X3) bernilai rata-rata sebesar 3,90 dengan kategori lumayan Tinggi. Yang artinya promosi product yang dilakukan shoopee menurut responden cukup baik dan dapat mempengaruhi konsumen untuk membeli.

4. Berdasarkan hasil perhitungan Menunjukkan analisis data dari variabel place (X4) dengan sampel 90 responden, tanggapan responden dari indicator variabel place $(\mathrm{X} 4)$ bernilai rata-rata sebesar 3,97 
dengan kategori lumayan Tinggi. Yang artinya mitra penjualyang menjual produk melalui aplikasi shoopee menurut responden dapat dipercaya dan mengirim barang sesuai dengan barang yang dibeli konsumen.

5. Berdasarkan hasil perhitungan Menunjukkan analisis data dari variabel partisipant(X5) dengan sampel 90 responden, tanggapan responden dari indicator variabel partisipant(X5) bernilai rata-rata sebesar 3,91 dengan kategori lumayan Tinggi. Yang artinya orang yang menjual produk melalui aplikasi shoopee menurut responden memberikan pelayanan yang sangat baik.

6. Berdasarkan hasil perhitungan Menunjukkan analisis data dari variabel proces(X3) dengan sampel 90 responden, tanggapan responden dari indicator variabel proces(X3) bernilai rata-rata sebesar 3,97 dengan kategori lumayan Tinggi. Yang artinya proses pembelian melalui aplikasi shoopee menurut responden mudah dan barang terkirim dengan cepat.

7. Berdasarkan hasil perhitungan Menunjukkan analisis data dari variabel Physical evidence (X7) dengan sampel 90 responden, tanggapan responden dari indicator variabel Physical evidence (X7) bernilai rata-rata sebesar 4,09 dengan kategori lumayan Tinggi.Yang artinya custumer percaya dan tidak takut dalam berbelanja melalui aplikasi shoopee karena shoope mempunyai kantor dan gudang sehingga custumer yakin tidak akan tertipu.

8. Berdasarkan hasil perhitungan Melihatkan analisis data dari variabel keputusan pembllian $(\mathrm{Y})$ dengan sampel 90 responden, tanggapan responden dari indicator variabel keputusan pembelian ( $Y$ ) bernilai mean 4,05 dengan kategori lumayan Tinggi. Yang artinya keputusan pembelian cutumer melalui aplikasi shoopee menurut responden cukup tinggi. Karena shoope sangat terkenal dan product yang dijual bagus dan harganya relative terjangkau.

Product, price, promotion, place, participant, process dan physical evidence secara simultan mempengarui dan signifikan dengan Keputusan Pembelian belanja online di SHOPEE pada Mahasiswa Prodi Manajemen Universitas PGRI Adi Buana Surabaya.

\section{IMPLIKASI}

1. Disarankan kepada Mahasiswa Prodi Manajemen Universitas PGRI Adi Buana Surabaya harus tetap pemperhatikan kualitas produk dalam membeli di shopee. Hal ini diharapkan nantinya barang yang dibeli dan diterima sesuai.

2. Disarankan kepada Mahasiswa Prodi Manajemen Universitas PGRI Adi Buana Surabaya harus mengecek harga sebelum membeli. Sehingga harga produk yang dibeli merupakan harga yang terendah namun kualitasnya sama.

3. Disarankan kepada Mahasiswa Prodi Manajemen Universitas PGRI Adi Buana Surabaya agar mengecek promo-promo sebelum melakukan pembelian barang pada shopee. Hal ini diharapkan mereka mendapatkan promo yang menarik yang diberikan oleh shopee.

4. Disarankan kepada Mahasiswa Prodi Manajemen Universitas PGRI Adi Buana Surabaya agar mengecek kejelasan penjual. Hal ini menghindari penipuan.

5. Disarankan kepada Mahasiswa Prodi Manajemen Universitas PGRI Adi Buana Surabaya agar menanyakan proses pengiriman barang setelah dilakukan pembayaran. Hal ini agar pengiriman sesuai dengan yang diharapkan.

6. Disarankan kepada peneliti selanjutnya yang mengambil judul yang sama agar dapat mengembangkan penelitian ini dengan menambah sampel penelitian. 


\section{DAFTAR PUSTAKA}

Amirullah. 2013. Metedologi Penelitian Manajemen. Malang: Bayumedia.

Daryanto. 2011. Manajemen Pemasaran: Sari Kuliah. Bandung: Satu Nusa.

Heizer, Jay dan Barry Render. 2015. Operations Management. Edisi 11. Penerjemah: Dwi Anoegrah Wati S dan Indra Almahdy. Jakarta: Salemba Empat.

Iskandar. 2012. Metedologi Penelitian Pendidikan dan Sosial (Kuantitatif dan Kualitatif). Jakarta: GP.

Kotler, Philip dan Keller, K.L. 2011. Manajemen Pemasaran. Edisi 13 Jilid 1 dan 2. Jakarta: Erlangga.

Kotler dan Keller. 2012. Manajemen Pemasaran. Edisi 12. Jakarta: Erlangga.

Lupiyoadi, Rambat dan A. Hamdani. 2011. Manajemen Pemasaran Jasa. Edisi Dua. Jakarta: Salemba Empat.

Munawaroh, Munjiati. 2013. Manajemen Operasi. Yogyakarta: LP3M UMY.

Sugiyono. 2012. Metode Penelitian Kuantitatif, Kualitatif dan R\&D. Bandung: Alfabeta.

Sugiyono. 2015. Metode Penelitian Kombinasi (Mix Methods). Bandung: Alfabeta.

Tjiptono, Fandy. 2010. Strategi Pemasaran. Edisi 2. Yogyakarta: Andi Offset.

Tjiptono, Fandy dan Gregorius Chandra. 2012. Pemasaran Strategik. Yogyakarta: Andi Offset.

Priyatno, Duwi. Mandiri Belajar Analisis Data Dengan SPSS. Yogyakarta: Mediakom.

www.kompas.com, 16 Mei 2019

www.marketeers.com, 25 Maret 2018

www.cnnindonesia.com, 31 Mei 2019 